\title{
The Case of Development Communication: Perspectives, Issues and Trends
}

\section{El caso de comunicación para el desarrollo: perspectivas, problemas y tendencias}

\author{
A.F. Mathew ${ }^{1}$
}

\begin{abstract}
The purpose of this paper is to provide an overview of development communication. To do so, the first section focuses on the theoretical perspective and evolution of development communication. The second section deals with selected examples from the Third World, and the final section is a summary.
\end{abstract}

Key words: Development communication, process, Third World, evolution.

\section{Resumen}

El propósito de este trabajo es proporcionar una visión general de comunicación para el desarrollo. Para este fin, la primera sección se centra en la perspectiva teórica y evolución de la comunicación para el desarrollo. La segunda sección trata de ejemplos seleccionados del Tercer Mundo, y la sección final es un resumen.

Palabras clave: comunicación para el desarrollo, proceso, Tercer Mundo, evolución.

1 Dr. Associate Professor, Mudra Institute of Communication (MICA), 


\section{Introduction to Development Communication}

Many notions persist with regard to both 'development' and 'communication'. How does one place the concept of Development Communication? At a very basic level, development communication would mean the notion that mass media are capable of creating a public atmosphere favorable to change, an aspect which is assumed to be invaluable for converting traditional societies into modern, through technological advancement and economic growth (Beltran, 1993). There are other related conceptualizations. There is the concept of Development Support Communication and the concept of Alternative Communication. These are specific in the sense that Development Support Communication holds the view that planned and organized communication is one of the key factors for the accomplishment of the goals of specific development seeking institutions and projects, whereas Alternative Communication for democratic development is the notion that by enhancing and balancing people's access to and participation in the communication process (at all levels then, development should secure, in addition to material gains, social justice and freedom) (Beltrán, 1993, p. 9).

It must be noted that the assumption that communication is one of the vital elements towards the process of development is assumed. This paper is going with that idea. At the outset, it remains clear that the media cannot take over the task of the community decision making group but they can feed the discussion or play a role. Any developing society must recognise the borderline as to where the media can work effectively by itself and where they can accomplish their goals only in support of interpersonal communication and other factors. This is essential (Schramm, 1964, p. 125). Here, Schramm also goes on to specify the communication tasks behind the social changes of national devel- opment which are three in nature. Firstly, the populace must have information about national development; the focus on the need for change, the opportunities inviting change, the methods and means of change and their aspirations. Secondly, there must be opportunity to participate in the decision process where in the dialogue broadened, the leaders have an opportunity to lead and the people to be heard, the issues of change to be made clear, the alternatives discussed and information to flow up and down the hierarchy. And third, the needed skills must be taught. Adults must be taught to read, children educated, farmers must be taught the methods of modern farming, training of both skilled and unskilled workers etc (Schramm, 1964, pp. 125125). Further more, these three communication tasks correspond to the three basic functions of communication that Schramm talks about (the watchman, decision maker and teacher functions). These are the fundamental tasks of communication. Among these basic tasks, which of these tasks can the mass media do by themselves and which can they only help to do? (Schramm, 1964, pp. 127-140).

The first group of tasks-the watchman, the informing functions are well within the realm of the media directly within which, the media can widen horizons, focus attention and can raise aspirations (of course, raising aspirations is not fraught with danger, in that process nothing could change except people's expectations). However, it is also true that by carrying political, economic, social and cultural reports from elsewhere in the country and the world, the media could also create a climate wherein

It must be noted that the assumption that communication is one of the vital elements towards the process of development is assumed. This paper is going with that idea. 
Volumen 13 Número 1 • Junio de 2010

people could take another look at their current practices and future perspectives (Schramm, 1964). The second group of fundamental tasksdecision making functions are for most part a function that the mass media can only help to do. This is because this requires group decision, the changing of strongly held attitudes, beliefs, social norms and hence here interpersonal communication comes into play (Schramm, 1964, pp. 127-140). Here the media helps in feeding information into the discussion, thus playing an indirect role in changing strongly held attitudes and valued practices. The third group of tasksthe teaching function could be both direct as well as indirect (in combination with interpersonal communication). For instance, in a classroom, the media can only be a supplement to a total educational experience under a classroom teacher but the media can substitute where in schools and teachers are not available. Similarly, radio cannot be a substitute to impart or teach a new agricultural skill but radio can be of great use for supplying additional information, reporting results etc. (Schramm 1964, pp. 127-140).

\section{Development Communication: Conceptual Evolution}

From the 1940 's to the 60 's, the age of the big media, the various communications approach to development included understanding in three areas (i) communication effects approach (ii) Diffusion of innovations approach and (iii) Mass Media and the modernization approach (Melkote, 1991, pp. 90-92). In the communications effects approach, the earliest models of mass media effects conceptualized the impact of mass media as direct, powerful and uniform on individuals living in "modern", industrial societies termed as "mass societies". Also, the earlier models (Lasswell, Shanon and Weaver etc.) saw communication as a linear and one way process flowing from a powerful source to a passive receiver (Melkote, 1991). After the II
Rogers applied further Katz and Lazarsfield's two step flow model that is, the two step flow process where the more aware can be accessed by the media and they in turn are instrumental in spreading the message to others.

world war, there was a change of opinion in the sense that realization dawned that mass media rather than being sole agents of attitudinal and behavioral change were more agents of reinforcement. Thus, early formulations did exhibit conceptual shortcomings that "stem from essentially the same idealist conception of history that informs the main sociological approach" (Hartmann, Patil and Dighe, 1989, p. 23). They were simplistic and in sufficient accounts of social and political dynamics of change and lacked an adequate conception of the relationship between culture and social structure (Hartmann, Patil and Dighe, 1989, p. 23).

However, the shift in emphasis regarding role of mass media from one of dominant and powerful influence to that of moderate or minimal effects did not make any significant difference of formulations advocating use of mass media for development in the III world countries. The view was that information and communication can be transferred to fields such as agricultural extension, health, education etc (Melkote, 1990). Diffusions of innovations approach has important theoretical links with effects research, wherein the ability of media and opinion leaders to bring about knowledge and new ideas among a target audience which would in turn lead to its adoption (Melkote, 1991).

Everette Roger's work is pioneering in this regard. He saw the diffusion of new ideas and practices as a crucial component of the modernization process (cited in Hartmann, Patil and Dighe, 1989, p. 25). Rogers applied further Katz 


\section{In the 1970's, it became abundantly clear that a the socio-economic scenario had diminished the promise of development communication.}

and Lazarsfield's two step flow model that is, the two step flow process where the more aware can be accessed by the media and they in turn are instrumental in spreading the message to others. "From the media to the opinion leader to the masses" (cited in Mcquail and Windahl, 1989 , p. 49). This was applied by Rogers to the study of the spread of agricultural innovations among farmers in the United State, and he identified the elements in the diffusion of an innovation. The five stages being awareness, interest, evaluation, trial and adoption which would, assuredly result in modernisation (cited in Hartmann, Patil and Dighe, 1989).

Further, the work that illustrated the modernization approach was proposed by Daniel Lerner in the "passing of Traditional Society" in 1958, a very influential work that assigned a very important role to communication (Ramos and Schramm, 1989, p. 12). Lerner identified four critical variables that he said summarized the development process: urbanization leading to increased literacy which in turn affects mass media exposure resulting in greater economic and political participation. A simple linear process but Lerner's most important hypothesis has to do with the nature of the 'modern individual' who is characterized by an ability to accommodate to change plus a high degree of empathy (Ramos and Schramm, 1989). According to him, people in traditional societies could expand their empathy by exposure to the mass media which in effect meant that mass media, in the third world, had the potential of bringing about modernization into isolated traditional communities and replacing the structure of life, values and behaviour which one sees in the western world (Melkote, 1991). Thus, research in this tradition created high expectations for the media's role towards development benefits in the third world. The whole approach up to the 60 's was that the media would make indigenous' audiences react favorably to opening up to the world and to the principles of market economy. "The desired changes (developmental) were connected to a vertical, elitist, relationship in which the "strong" were "helping" and "weak" to be seduced by the blessings of science and technology, which were perceived as being exclusively western "inventors" (Habib, 1993, p. 65).

In the 1970's, it became abundantly clear that a the socio-economic scenario had diminished the promise of development communication. Mass media proved not to be an independent variable but itself was subject to various situational, political, social and economic factors (Melkote, 1991, pp. 172-173). New approaches were broached upon primarily because there was wide ideological debate categories such as (Habib, 1993, pp. 65-66) analysis of the ownership of media structure, international structures for transmission and production of information, class analysis of the communication process, the political economy of communications, the appeal for an inauguration of a north south dialogue towards a new world order of information, all these started being discussed and thought about, a process that continues till today (Habib, 1993, pp. 65-66). These debates arose because of the rising belief that the communication models and theories are basically exported from the first world and that they were suited only to explain the media phenomena in those societies, rooted in that a cultural tradition.

There was then, a progressive reflection on the "state of development" achieved up to the 60's wherein the situation of the very poor had only but deteriorated. From the $70^{\prime}$ s the stress was on (i) equity in distribution of information and other 
benefits of development (ii) active participation of people at the grassroots (iii) Independence of local communities to tailor development projects to their own objectives and (iv) integration of the old and new ideas, the traditional and modern systems suited to the needs of a community (Melkote, 1991, pp. 225-226). Paulo Freire's views in the 60's and 70's also challenged critically commonly accepted notions of communication. He condemned traditional literacy training as authoritarian in which the teachers "deposit" the set of values of the rich in the poor, who can later "cash in" on those "deposits" for material goods given to them as reward for passivity (Beltran, 1989). Genuine communication, he said is free dialogue actively sharing and reconstructing experience, education is the creative discovery of the world, not transmission of knowledge from the powerful to the powerless. Freire, in effect, proposed 'conscientisation' as a democratic method for people to gain collective awareness of natural and social realities, a method that is based on non-directed discussion of individual and cultural problems in small cultural circles, stimulated only by 'generative words' selected from the people's 'minimum thematic universe' (Beltrán, 1989, p. 16). This would, in turn show the exploited that society is changeable (Beltrán, 1989).

The interrelation of Freire's ideas to the process of development education is evident (Beltran, 1989: 16). For example, Freire regarded the transplantation of the agricultural extension program of the United States as opposite to true educational practice because it came with the assumption that it came from the "seat of wisdom to the seat of ignorance" (Beltrán, 1989, p. 16).

In summation, two paradigms on communication and development comes through in the evolutionary process during the last five decades - the Modernisation Paradigm and the Dependency Paradigm. The Modernisation Paradigm spelled out development as a spontaneous, uni- linear and irreversible process which in turn implied functional specialisation (Servaes, 1996, p. 83). In this, development was to be stimulated by external, endogenous factors and by internal measures geared towards supporting modern sectors and modernising traditional sectors (Servaes, 1996, p. 83).

In the Dependency Paradigm, the whole development process was towards the philosophy of disassociation from the world market in goal of self-reliance as the most important perceived obstacle to development are external to the underdeveloped nation (Servaes, 1996). None of these 'paradigms' explained the dismal record of economic and social development in the third world. For instance, by 1980, after two UN “Development Decades", the developing countries had accumulated a foreign debt of nearly $\$ 440$ billion, a figure that was only $\$ 68$ billion in 1971 (Beltrán, 1989, p. 12). Three fourths of the world population accounted for only 20 per cent of the world's gross product, and Asia, Africa and Latin America, which were net exporters of foodgrains before the second world war are regions constantly affected by major famines today (Beltrán, 1989, p. 12). The entire disparity of resources between the first world and the third world, gets extended to media too, implying a failure of communication as a factor to encourage development in the third world. Also, it is not just a question of external exploitation or scarcity of resources but also that of unequal distribution of resources within the third world (Beltrán, 1989). All these viewpoints, realisations and shifts in theory has resulted in the third approach/paradigm called the Multiplicity Paradigm (Servaes, 1996, pp. 84-85). This paradigm spelled out the following (Servaes, 1996):

- All nations are interdependent and consequently, internal as well as external factors influence the development process. 
- The entire development process has to be studied in a global context wherein more attention should be paid to the content of development implying a more normative approach.

- Each society must develop its own development strategy for there is no universal model for development.

This new approach has emerged from the criticism of the modernisation and dependency paradigms and it should be seen from the perspective of selfdevelopment of the local community through its participation. Contemporary development communication places a great deal of emphasis on self help, and grass root participation. This has led to a reexamination of the advantages of the traditional media as vehicles for information, persuasion of the rural masses (Melkote, 1991). Folk media is part of the social milieu of the people, hence credible sources of information for the people. They also generate grass root participation and a dialogue between performances and the audience. They are also, flexible and hence, developmental themes can be incorporated in them (Melkote, 1991). On the whole, development communication is and it should be geared towards the basic needs of people and their participation.

\section{A Theoretical Perspective}

In light of the historical crisis of development in terms of different paradigms mentioned above, one could state that any theoretical construction should re-examine the normative and historical contents of the two concepts of communication and development. The processes of social communication and development are complex processes that appear different from the perspectives of the top/bottom or centre/periphery, of a social system (Tehranian, 1996, pp. 49-51). The following table attempts to capture some of these contradictory perspectives:

Conflicts of interest and perception are thus at the very centre of the development process and they get reflected in terms of ideologies and com-

Table 1

Contradictory Perspectives on Communication and Development Goals

\begin{tabular}{|l|l|}
\hline $\begin{array}{c}\text { Communication and Development Goals } \\
\text { Viewed from Top/Center }\end{array}$ & $\begin{array}{c}\text { Communication and Development Goals } \\
\text { Viewed from Bottom/Periphery }\end{array}$ \\
\hline National security and power & $\begin{array}{l}\text { Group/Individual choice and freedom } \\
\text { Social and political mobilization }\end{array}$ \\
National unity and identity & $\begin{array}{l}\text { Subnational unity and identity } \\
\text { Economic growth }\end{array}$ \\
Political socialization & Political participation \\
Education/professional competence & Education/professional opportunities \\
Information control & Information access \\
Communication surveillance & Communication privacy \\
Government authority & Citizen power \\
Central authority and control & Regional and local autonomy \\
Cultural and artistic direction & Cultural and artistic creativity \\
(sometimes censorship) & (sometimes subversion) \\
\hline
\end{tabular}

Source: Tehrnian, 1996: 50 
Table 2

Contradictory Processes and Perspectives in Development

\begin{tabular}{|c|c|c|c|}
\hline DIMENSIONS & $\begin{array}{c}\text { GENERATORS } \\
\text { Top-down Views }\end{array}$ & $\begin{array}{c}\text { DETERRENTS } \\
\text { Bottom-up Views }\end{array}$ & $\begin{array}{c}\text { CRSES } \\
\text { Democratic Views }\end{array}$ \\
\hline Economic & Accumulation & Concentration & Distribution: Equality \\
Political & Mobilization & Repression & Participation: Freedom \\
Socio-cultural & Differentiation & Domination & Integration: Community \\
\hline
\end{tabular}

Source: Tehranian, 1996: 51

munication strategies (top-down/bottom-up) (Tehranian, 1996). Table 1 reduces these processes to three fundamental and contradictory ones, viewed from the three perspectives topdown, bottom-up and democratic perspectives. If we consider the processes mentioned in Ta- ble 2, the historical crisis of development can be viewed as a distribution crisis is to fulfil the promise of equality, a participation crisis to fulfil the promise of freedom, and an integration crisis to achieve a sense of community (Tehranian, 1996, p. 50).

\section{Social Structure Influences Culture}

\begin{tabular}{lccc|}
\multicolumn{1}{c}{} & \multicolumn{1}{c}{ Yes } & No \\
\cline { 3 - 4 } Culture influences & Yes & $\begin{array}{c}\text { Interdependence } \\
\text { (Two way } \\
\text { influence) }\end{array}$ & $\begin{array}{c}\text { Idealism } \\
\text { strong media } \\
\text { influence }\end{array}$ \\
\cline { 3 - 4 } Social Structure & No & Materialism & Autonomy \\
& & (Media is & No casual \\
& & connection
\end{tabular}

In terms of media theory, most of which relates to both society and culture together. Obviously, society and culture are inseparable. For the present purpose, society refers to the material base (economic, political resources and power) to relationships in various social collectives (nation, community and family) (Mcquail, 1994). It has to be noted that the history of modern society has usually been written in terms of a materially driven process, with society as a 'base' and culture as superstructure'. Culture, herein, refers to other essential aspects of collective social life, especially to meanings and practices (Mcquail, 1994). Mass communication can be both societal and cultural phenomena (Rosengren, 1981, pp. 47-63).

Rosengren identifies four main option available for describing mass media and society. If we consider mass media as an aspect of base, then it is the option of materialism where in the culture is dependent on the economic and power structure of a society. What is then assumed is that whoever owns or controls the media chooses and sets the limit to what they do and can do. It is in the light of the media content that the option of idealism is presented. It is opposite to the earlier option wherein, here, it is believed that it is the media 
content, ideas and values conveyed by the media that seen as a cause of social change, irrespective of who owns and controls. Interdependence implies that mass media and society are continually interaction and influencing each other, in which, the media responds on a continuous basis to the demands of society, also innovates to a changing socio-cultural climate which in turn sets off new demands. The autonomy option does not go with this view in the sense that it is likely that society and mass media can vary independently upto a point. This goes with the view of critics who are skeptical about the power of the media to influence ideas, values or behaviors (Rosengern, 1981, pp. 247-63). Going further would be to seek a frame of reference for connecting media and society (Mcquail, 1994, pp. 7-8) as below:

The above representation points out to the fact that media institutions are not independent in relation to the rest of society, they too being subject to rules, influences etc. All elements in the figure are dependent on each other. People/masses acquire information and meaning of "reality" via direct observation and experience, from institutions directly, from institutions via the media and from the media autonomously and the influence of larger events and of economic and political forces comes partly channeled from the mass media (Mcquail, 1994, p. 9) However, what is ambiguous in the representation is whether media institutions would be able to assert itself minus controls specified when any such situation arises (Mcquail, 1994). However, one must also recognize that the media operates in a society where the power structure is distributed unevenly between the classes. It is related to the prevailing structure of political and economic power.

In this context, two models of media power one of dominant media and the other of pluralist media can be mentioned, figure as shown below (Mcquail, 1994). The dominant media model sees media as a subservient part of other institution which themselves are interrelated. The media is owned by a small number of powerful people which disseminate a limited view of the ruling classes. The masses are given a limited view, with no critical feedback which results into an attempt to legitimize the existing power structure. The pluralist model is exactly the opposite where it is held that there is no unified and dominant elite and change and control are both possible. In this model, the masses can differentiate, initiate demand and can react to what the media offers (Mcquail, 1994). This does not close, the option of a "mixed approach" where mass domination are within limits and counter forces are resisted by the audience/masses (Mcquail, 1994).

The dominant media model reflects the mass society view (Mcquail, 1994: 74). Mass society refers to the relationship between individuals and social order around them where in individuals are presumed to be in a situation of 'psychological isolation' from others, impersonality in their interactions with others and are relatively free from the demands of binding informal social obligations, view carried by some sociologists well into the 20th century (DeFleur, Rokeach, 1989, pp. 148-160). Putting these ideas onto the media, it would mean, an atomized public, centralized media, one way transmission, media being used for control and/or manipulation and people using media for identity (Mcquail, 1994, p. 75).

As for the Marxist perspective, power is central to its interpretations of the media, that they are an instrument to propagate the interests of the ruling class. There is a direct link between ownership and dissemination of messages, in the sense that content of media is also organized towards further propagation of the interests of the capitalist class (Herman and Chomsky, 1988). In essence, Marxist view of the media could be summed up by saying that media is owned by the bourgeois, thus operating their class interests thus working towards false consciousness. Media access is denied to the ideologically political opposition (Mcquail 1994, p. 77). 


\begin{tabular}{|c|c|c|}
\hline & DOMINANCE & PLURALISM \\
\hline Societal source & Dominant elite/Ruling classes & $\begin{array}{l}\text { Competing political social, } \\
\text { cultural interests a group }\end{array}$ \\
\hline Media & Under concentrated ownership & Many and independent to each other \\
\hline Production & Standardised, controlled & Free, "creative" Original \\
\hline Content and world view & Selective and uniform & $\begin{array}{l}\text { Diverse, competing views, } \\
\text { respective to audience demands }\end{array}$ \\
\hline Audience & Dependent, passive organised on a scale & Fragmented, selective, reactive/active \\
\hline Effects & $\begin{array}{l}\text { Strong and confirmative of } \\
\text { established social order. }\end{array}$ & $\begin{array}{c}\text { Numerous, without consistency } \\
\text { of predictability of direction but } \\
\text { often no effect. }\end{array}$ \\
\hline
\end{tabular}

The neo-Marxists go further to other ideas rather than focus only on material structures. The view is that media reproduces exploitative relationships and manipulation. It is an "ideological state apparatus" which enables the capitalist state to survive, this without the help of other institutions like the army or police (Althusser, 1971). This is closely related to the concept of hegemony where there is an internally consistent culture and ideology favorable to the dominant elite/class (in Hoare and Smith, 1996). Gramsci states that the relationship between the intellectuals and the world of production is not as direct as it is with fundamental social groups, but is in varying degrees mediated by the whole fabric of society, and by the complex of superstructures, of which intellectuals are, precisely the "functionaries" (in Hoare and Smith, 1996, p. 12). There are two major super structural "levels", one that can be called civil society (group of organisms called "private") and that of "political society" or the "state". Both these levels correspond to hegemony which the elite/dominant exercises in society. The "intellectuals" are the dominant groups exercising the function of hegemony and political government (in Hoare and Smith, 1996). Further more, Gramsci explains that the "spontaneous" consent given by the mass to the direction imposed on social life by the dominant group is "historically" caused by the prestige and confidence the dominant group enjoy because of its position and function in the world of production.

The functionalist theory of media says that more an audience is reliant on the mass media for information and more a society is in a state of crisis then more the power the media is likely to have. This functionalist approach has been criticised for its inadequacy in dealing with issues of power and conflict but one can see how the media are functional in the exercise of power (Mcquail, 1994), (Functionalism claims to explain social practices and institutions in terms of needs of the society and individual). As per this view, media is considered essential to society for integration, co-operation, order, control, stability, mobilization, continuity of values and culture (Mcquail, 1994: 81).

\section{Select Examples of Development Communication from the Developing Countries}

From the very beginning, mass media for development communication was seen as a substitute for unavailable teachers, field agents or as a complement to inadequately trained personnel 
(Hornik, 1989). In the early years, radio or television was an enrichment to existing classroom instruction, for example, weekly broadcast might include a dramatic presentation of some event in the nation's history to enrich the social sciences' curriculum. This approach, however, was contributory in the developed nation but would it fit into third world schools which are plagued with lack of resources, facilities and high drop out rates? (Hornik, 1989, p. 18). But there have been examples of constructive and supportive use of mass media in the third world. Some select examples are cited below.

Two of the most significant and long lasting experience with development communication started in 1948 in Columbia and Bolivia. Incidentally, in Latin America the communication media are characterized by opulence rather than misery (Roncagliolo, 1993, p. 33). In the sense that, on an average, one out of every three people in Latin America owns a radio and one out of every seven people owns a television set, broadcast time or four times the viewing time of Latin countries in Europe (Spain, France Italy, Portugal, and Rumania) and also there is excess of television stations. Bolivia, for instance, has one of the highest television channels per-viewer rates, more than one television channel for every 10,000 viewers (Roncagliolo, 1993, p. 33). It has to be noted, here, that in a consumer society, all the above figures are only remotely related to socio economic level of development (Roncagliolo, 1993).

Coming back to actual media projects in development in 1948, in Colombia, a parish priest, Joaquin Salcedo established one of the most significant communication for development project (Beltrán, 1993). The priest established a rudimentary broadcasting station for peasants in an Andean village. This Radio Sutatenza had the purpose of expanding Catholic indoctrination and helping reduce illiteracy (Beltrán, 1993). Gradually, it picked up and this individual ini- tiative evolved to become the Accion Cathedral Popular (ACPO) which is one of the most influential multimedia institutions of non-formal distance education for rural development, whose strategy was group discussion and listening of special programs assisted by a local trainee and print materials (Beltrán,1993). These initiatives led to many more in Latin America. Some are briefly noted below (Beltrán, 1993, pp. 16-18):

- In Uruguay Mario Kaplun designed and tested a new strategy: rural cassette forums which was a low cost procedure for dialogue of at distance among members of peasant co-operatives.

- In Ecuador, a Catholic Priest led the small, isolated Indian community to participate in broadcasting by recording news messages and brief programs in their own villages and then sending them to a central station.

- In Bolivia, peasants rented the early mornings (hours) of commercial broadcast stations in La Paz and in Aymara, they undertook an unusual and pioneering exercise in democratic communication when they provided through radio the equivalent to the postal, telegraph and telephone services not available in the countryside.

In Peru, Michacl Azcueta and others built a whole system of remarkable grassroots communications in a huge Lima slum populated by migrant native peasants.

\section{The Popular Culture Action of Honduras (ACPH)}

This was inspired by the earlier mentioned Colombian experiment. It was White (1976) (cited In Jamison and McanaUy, 1978: 79-84) who undertook an evaluation of ACPH, which was a long term evaluation. White states that in Honduras, the large landholder as the key powerholder and link with the urban elite, as is the case generally 
Volumen 13 Número 1 • Junio de 2010

Before the revolution, Cuban television and radio was already well developed. In 1959, after the revolution the Radio and TV Commission was established and an experimental project in educational television was launched for primary school viewing.

in Latin America. He points out that with the coming of "modernisation" and the greater concentration of land and technology in the hands the landlords, the peasant's level of subsistence worsened (Jamison and Mcanuy, 1978, p. 79). During the 60 's, the ACPH began focussing on issues such as literacy, health, and raising the campesino's (peasant) level of consciousness (Jamison and Mcanuy, 1978). It was noted in the evaluation study, that the ACPH along with its companion peasant movement Popular Promotion Movement (PPM) moved from the original emphasis on literacy to stages of Freirean consciousness raising, community organizing to a final action oriented, pressure group phase of pushing for greater social and economic power (cited In Jaimison and Mcanauy 1978, p. 79).

White evaluated the effectiveness of the literacy work of the radio schools for the ten year period (1961-70) by taking a sample of 595 students (or ex) of ACPH and testing them for literacy skills. It was found that those who, had at least one or two years of regular school, that made the difference to literacy attainment rather than only radio classes. It was argued that the PPM policy after 1972, to organize and pressure the government for land, should make literacy more relevant in Honduras (cited in Jamison and Mcanauy 1978, p. 82).

It was found that in radio school villages knowledge was high in health and agriculture but only in health were they higher in practice, when compared to non radio villages. The lack of success of ACPH/PPM in farm practice was because knowledge without resource inputs does not help the farmer. For organisation principles for collective action, it was found that radio villages had a higher level of consciousness, did not find apparent greater organizational skills in radio villages but did find that radio villages had carried out more community projects. However, it was noted that direct political work among the peasants did not take place. They were not prepared by the programmes. On the whole, "the ACPH/PPM helped create a new "campesino" culture and helped develop a participating decision making structure and helped develop a base for interest group action" (Jamison and Mcanauy, 1978, p. 83).

\section{Cuban Media and Education}

Before the revolution, Cuban television and radio was already well developed. In 1959, after the revolution the Radio and TV Commission was established and an experimental project in educational television was launched for primary school viewing. Teleclasses with supporting written material were given, classes were broadcast daily, one subject per day for half an hour. A daily newspaper "free press" published every Friday the week's schedule.This was also extended to junior high schools in a similar manner. A 1960 survey revealed that an average audience was of 2,00,000 persons, two-thirds of them teacher and students and the remaining third adults who had no direct links with the existing educational system (Gerbner, 1977).

In 1961, the year of education, the well known literacy campaign was initiated. Television and radio played a complementary role in the dissemination of literacy training programs. Live coverage of literacy worker and students was used to dramatise and this was reinforced on radio and in newspapers. Of the 4,50,000 adults 


\section{The impact was much higher than expected and it was observed that more people were bringing their children to be immunized, visiting family planning clinics, asking for fertilizer etc.}

enrolled in the adult education courses, about $3,00,000$ were reached by teleclasses. After the initial basic courses, specialized courses were also broadcast.

In 1966, the media played a major role in the "schools of the countryside" program which was first implemented in the province of Camaguey (Gerbner, 1977). That was aimed at reducing differences between city and country and for educating new generation in and for work. All this and more resulted in putting great strain on the secondary level in 1969 (earlier a huge number of students had entered at the primary level). This great demand for teachers and schools was filled up by television and radio (Gerbner, 1977). Teleteachers were trained and also, in the classrooms more advanced students acted as monitors to clarify material and help students. This entire exercise was coordinated by the Cuban Ministry of Education and the Cuban Broadcasting Institute (ICR). The Cuban example is a pointer to how supportive the media could be towards a common, collective and mobilized developmental goal, but one must be aware of the socio-political context that the whole process took place. The revolutionary spirit abetted the whole process.

\section{The Liberian Rural Communication Network}

The Liberian Rural Communication Network (LRCN) consisted of a network of three 10,000 watt stations supported by a central production in Monrovia. Even though the administrative unit was in the capital but three fourths programming emanated from local stations. The stations broadcast a total of six hours in the morning and evening and each station established a strong local identity and was guided in its programming by local advisory committees (Laflin, 1993, p. 105). The main sources of funding was from the government of Liberia. LCRN was designed to promote community development in several ways: (i) Promoting increased use of government services by the rural population (LRCN worked closely with government services) (ii) Expanding the access to development and other services to a greater portion of the rural population. Towards this, LRCN always tried to ensure that both urban as well as rural areas were well served. Village stringers were recreated and trained and listening groups established. A majority of $55 \%$ of rural Liberians who listened to LRCN stations considered the programmes as their primary source of development information (Laflin, 1993, p. 105) (iii) Increasing communication between villages and the local, regional and national governments. Rural people were provided access through interviews in special programs which was in turn seen by government officials at the highest level. LRCN was also instrumental in increasing self help activities and promoted establishment of vegetable gardens, village health committees, individual clinics, hospitals, local drama groups and soccer teams. (v) News, especially of local revelance was disseminated through LRCN.

The impact was much higher than expected and it was observed that more people were bringing their children to be immunized, visiting family planning clinics, asking for fertilizer etc. An independent evaluation showed that there was narrowing of the knowledge gap about family planning, health, agriculture and nutrition between urban and rural listeners, that there was a daily listening audience of $55 \%$, a regular listener 
ship of about $75 \%$ and that most of the success achieved was because traditional sources of information was the primary source for many issues (Laflin, 1993, p. 107). Hence, the programme could be deemed as successful as long as the democratic system/spirit prevailed but as is the case in many third world nations, Liberia too fell into the abyss of civil war further crippling the emancipation process through development.

In retrospect, the $\mathrm{ACPH}$ and $\mathrm{LRCN}$ development communication projects were within the framework of the concept of Development Support Communication (mentioned earlier). In the sense that, it went with the view that planned and organised communication held the key to development projects. The Cuban experience could come under the purview of Alternative Communication for the experiment was designed with the idea of people's mobilisation and towards enhancing the masses' access and participation in the communication process.

\section{An 'End Note'}

When one sees the present world status in terms of the social, political or economic, one does one wonder the 'future' of Development Communication. About one billion people are living in utter poverty and some 70 percent of world income produced, is being consumed by 15 percent of the world's population (Golding, 1996, p. 82). In mass communications too, the figures are alarming. For example, book production is dominated by Europe and the United States, half of the production of newspapers remains in the west. Africa has just one percent of the world's newspaper circulation, Africa has just 3.7 percent of the radios and 1.3 percent of television sets with 12.1 percent of the population whereas Europe and the US together with $20.1 \%$ of the population has two thirds of the total of the world's television and radio (Golding, 1996, pp. 82-83.) The Internet also provides a similar picture. In terms of number of networks linked to the inter- net there is a vast discrepancy. The United States has the largest with 17,902, UK having 1,395, Russia, 229, Japan 1,379, Chile 47, Kuwait 5 and China three networks linked to the net (Strasser, 1994, p. 23). In terms of users, there were, as per internet society estimates, only 0.002 users per 1000 inhabitants in India compared to 48.9 in Sweden (cited in Golding, 1996).

However the emphatic vision that is the "information Highway" has grown phenomenally with the World Wide Web. This refers to an enormously expanded system of interactive communication based on the convergence of the personal computer, the telephone and the television, within a single network (Dawson and Foster, 1996, p. 41). The expectation of business and government planners is that eventually most personal computers will be connected into an interactive network that transcends the present internet. The general technological character of the new system is not in doubt, nor is there any doubt about the potential of the new technology to revolutionize human communication; but being aware of the existing vast gap between the haves and have nots, it is debatable as to what purpose the system will serve or who will benefit (Dawson and Foster, 1996). "Indeed, history has shown that every technological revolution in communications-no matter what its potential for democratization has been-has lent itself to the growth of new monopolizes of information when inscribed within existing system of social and economic power. Whether this will happen once again will not be determined by the nature

Another pertinent question that needs

to be asked is that is it feasible for countries possessing a billion peasants to invest vast sums on the technologies like the Information Highway when even basic indicators in health, education, etc., have not been achieved. 
of the technology itself but by the degree of determination and organisation of popular forces" (Dawson and Foster 1996, p. 42).

Another pertinent question that needs to be asked is that is it feasible for countries possessing a billion peasants to invest vast sums on the technologies like the Information Highway when even basic indicators in health, education, etc., have not been achieved. Other related issues concerning the third world also remain; that of corrupt regimes, the persistent consolidation of exploitative ruling elites, protection of special interests, military spending, bureaucratic ineptitude etc. (Kennedy, 1993, p. 61). Until profound changes occur, it is hard to foresee when Ethiopian based companies flush with funds and talent begin to move into Japan or the US, to take their historic turn at the centre of the global economic stage (Kennedy, 1993, p. 61).

\section{Summation}

Media use in development process has enormous scope. Media/mass communication cannot exist by itself or solve the problems of development by itself. One cannot exclude social, cultural, political and economic factors. Development communication should be integrated as part of the broader system of developmental planning and community programs. One must not overlook the aspect of cooption through the aid of media within systems. Development Communication Programmes should not aid the aspect of cooption consciously or unconsciously. Thus, it becomes evident that the utility of the media and the way it is used depends upon the political will exercised. A considerable amount of progressive political will is required for the constructive use of mass communications for developmental purposes towards the goal of emancipation of the underprivileged.

From the case studies of the Cuban, Liberian and the Honduras experiment, one gathers that it is imperative that media be taken to the deprived areas where the oppressed could not only have access but also participate in the developmental process. The evaluation of these developmental projects reveals that media inputs did help in a major way to spread awareness, literacy and knowledge. A vertical trajectory that descends from the city to the village or from the rich to the poor would not work while employing the media for developmental purposes. There should be constant feedback and grassroots participation. Hence, it follows that while project planning takes place, the local cultural milieu should only be kept in mind. Only the local language, customs, culture should be adopted otherwise acceptability to that developmental media project will not be there. Development communication theory/ models should, hence, be rooted within the local cultural milieu rather than as western models that needs to be applied to third world settings.

One must also recognize the fact that development communication is expensive especially when it comes to satellites or computer communications. However, there is need to establish a basic infrastructure for media in the third world. Without doubt, it would only pay if essential investments are made towards infrastructure in this field as the benefits would only pay in the long run. The vast disparity and widening inequalities and the reasons why they have occurred, must be recognised and all tools of development communication should be first geared to tackle these issues. Until then the concept of global village would remain an elusive myth. What is also crucial is the vital question as to what is the role of media in a system which has given us Bosnia, Chechnya, Darfur, Palestine, Iraq, Afghanistan, Kashmir or many such examples?

\section{References}

Althuser, L. (1971). "Ideology and Ideological State Apparatus", Lenin and Philolsophy and Other Essays. London: W.Left Books. 
Beltrán, Luis Ramiro. (1989). "Alternative Systems", International Encyclopedia of Communication. New York: Oxford University Press, Vol. 2.

Beltrán, Luis Ramiro. (1993). Cultural Expression in the Global Village, (ed). David Nostbakken and Charles Morrow. Penang: Southbound Publishers, pp. 9-31.

DeFleur, Melvin and Rokeach, Sandra. (1994), Mass Communication Theory. London: Sage Publications.

Gerbner, George. (1977). Mass Media Policies in Changing Cultures. New York: John Wiley and Sons, pp. 131-133.

Golding. Peter. (1996). "World Wide Wedge: Development and Contradiction in the Global Information Infrastructure", Monthly Review. Vol. 58, No. 3, July-Aug.

Habib, Jacques. (1993), Cultural Expression in the Global Village. (ed.). David Nostbakken and Charles Morrow. Penang: Southbound Publishers.

Hartmann, Paul; Patil, B.R.; and Dighe, Amita. (1989). The Mass Media and Village Life, New Delhi: Sage Publications.

Hoare, Quintin and Smith, Geoffrey (eds.). (1996), Selections from the Prison Notebook of Gramsci. Madras: Orient Longman Ltd.

Hornik, Robert, C. (1989). "Projects", International Encyclopedia of Communication. New York: Oxford University Press.

Jamison, Dean, T., Mcauany, Emile, G. (1978). Radio for Education and Development. London: Sage Publishers.

Kennedy, Paul. (1993). Cultural Expression in the Global Village. (ed.). David Nostbakken and Charles Morrow. Penang: Southbound Publishers.
Mcquail, Dennis. (1994). Mass Communication Theory. London: Sage Publications.

Mcquail, Dennis; Windahl, Sven. (1989). Communcation Models. New York: Longman.

Melkote, Srinivas. (1991). Communication for Development in the Third World, New Delhi: Sage Publications, pp. 90-92, 172-173, 225-227, 270-271.

Ramos, Hernandez and Schramm, Wilbur. (1989). "History and Theories", International Encyclopedia of Communication. New York: Oxford Univesity Press, Vol. 2.

Roncagliolo, Rafael. (1993). Cultural Expression in the Global Village. (ed.). David Nostbakken and Charles Morrow. Penang: Southbound Publishers.

Rosengren, K. E. (1981). "Mass Media and Social Changes, Some Current Approaches", in E. Kaltz and T. Szesko (eds.). Mass Media and Social Change. London: Sage Publishers.

Schramm, Wilbur. (1964). Mass Communication and National Development. California: Stanford University Press.

Servaes, Jan. (1996). “Participatory Communication Research with Social Movements", in Participatory Communication for Social Change. (ed.). Servaes, J. Jacobson, T. and White, S. London: Sage Publications.

Strasser, Steven. (1994). "Can you dial us in? Newsweek. New York: June 6, pp. 20-23.

Tehranian, Majid. (1996). "Communication, Participation and Development", in Participatory Communication for Social Change. (ed.). Servaes, J. Jacobson, T. and White, S. London: Sage Publications. 